\title{
TEORIA DAS RESTRIÇÕES (TOC): CASO DE APLICAÇÃO EM UMA EMPRESA DE CONFECÇÃO
}

\section{THEORY OF CONSTRAINTS (TOC): A CASE IN A WEAR MANUFACTURING COMPANY}

\author{
Fábio Gonçalves Torres ${ }^{1}$; Helder Gomes Costa $^{2}$ \\ ${ }^{1}$ Universidade Federal Fluminense - UFF-Niterói - Brasil \\ fabio@tred.com.br \\ ${ }^{2}$ Universidade Federal Fluminense - UFF-Niterói - Brasil \\ hgc@.pg.cnpq.br
}

\begin{abstract}
Resumo
Este artigo apresenta uma análise de um caso de aplicação da Teoria das Restrições (TOC) para o planejamento de um sistema de produção. A aplicação foi efetuada em uma empresa do ramo de confecção com 17 empregados à época da pesquisa, estando situada na cidade de Juiz de Fora, MG, Brasil. Os dados foram coletados entre 01/02/2010 à 5/02/2010. Durante a modelagem foram identificados os fluxos de produção e mapeados os tempos de operação em cada uma das estações de trabalho, as quais eram operadas manualmente. A modelagem e análise do sistema de produção também envolveram um estudo de sensibilidade dos resultados nos quesitos custo e tempo total de produção. Os resultados obtidos permitiram identificar e elevar os gargalos de produção, além de possibilitar a escolha da opção mais adequada para a configuração do sistema de produção.
\end{abstract}

Palavras chave: teoria das restrições; gestão de processos; gestão de sistemas de produção; confecção.

\section{Introdução}

A indústria de confecções brasileira possuía em 2009, 25.666 confecções e foi responsável por gerar 1.639 .900 empregos, ou seja, 17,1\% do emprego total da indústria de transformação nacional, se tornando a $5^{\mathrm{a}}$ maior produtora mundial de têxteis e vestuário de acordo com o IEMI (2010). A época deste levantamento a indústria de confecções consumia internamente mais de $90 \%$ do que produzia e respondia por um faturamento de US\$ 47,4 bilhões. Junto com os têxteis, o setor representou cerca de $5,7 \%$ do total gerado pela indústria de transformação, que foi de US\$ 826,4 bilhões. Esses dados expressam o potencial e a importância dessa indústria na economia brasileira. A Figura 1 apresenta a estrutura da cadeia produtiva têxtil.

Na cidade de Juiz de Fora a importância das indústrias têxtil e de confecções remontam o início do período de industrialização do município entre 1880 a 1930 sendo conhecida como 
"Manchester Mineira" tamanha a sua expansão no setor. Atualmente Juiz de Fora é o terceiro município do Estado de Minas Gerais em números de estabelecimentos, contando com 961 empresas e respondendo por $30,6 \%$ dos postos de trabalho no segmento industrial da cidade. (FIEMG/IEL-MG/SINDVEST/JF, 2008).

Figura 1 - Estrutura da cadeia produtiva têxtil

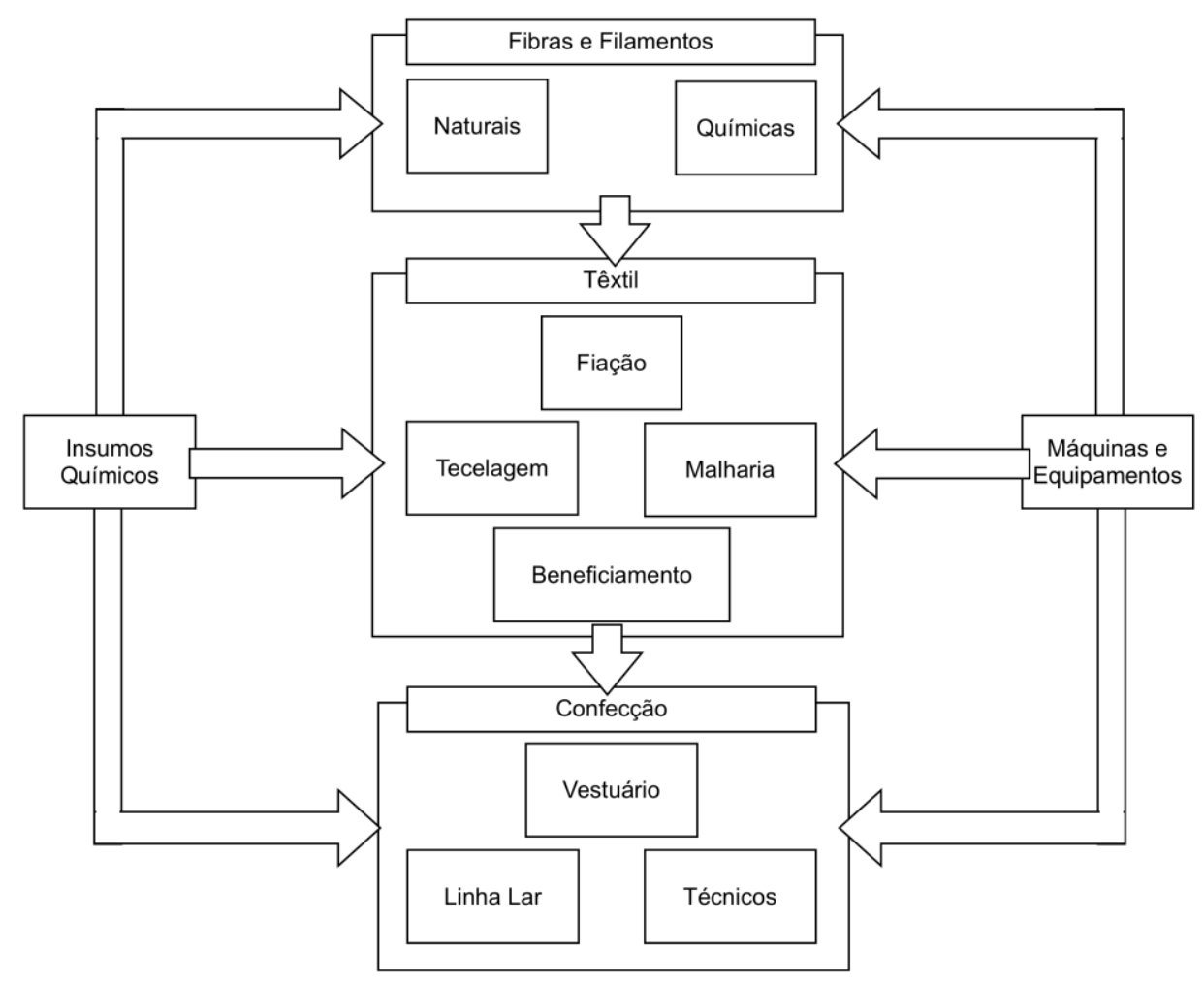

Fonte: IEMI (2010)

De acordo com o último "Diagnóstico das indústrias têxteis e do vestuário de Juiz de Fora" (FIEMG/IEL-MG/SINDVEST/JF, 2008) foi apontada a necessidade de melhores controles dos sistemas de estoques, dos custos e da produtividade das empresas, entre outros. Para conseguirem se manter competitivas as empresas precisam desenvolver técnicas e adquirir novos conhecimentos que as mantenham atualizadas. Dessa forma, este estudo contribui para que o setor de confecção possa explorar seus gargalos em busca de eficiência, tornando-se mais competitivas, por meio da aplicação da TOC.

Este trabalho tem por objetivo apresentar uma modelagem sobre a aplicação da TOC em um sistema de produção de uma confecção. Para tal foi realizada inicialmente uma revisão bibliográfica com o objetivo de identificar os principais conceitos desenvolvidos pela Teoria. Após a revisão foi efetuada uma modelagem a fim de realizar a implantação da TOC para o planejamento do sistema de produção da empresa.

Este artigo se divide em três partes: modelagem e aplicação dos conceitos da TOC; aplicação dos cinco passos de focalização da TOC e análise da aplicação. 


\subsection{Revisão bibliográfica}

A teoria das restrições (Theory of Constraints, TOC) foi proposta em Goldratt (1998), como uma forma de gestão baseada em gerenciamento de gargalos, contrapondo-se aos modelos tradicionais, baseados nos modelos de "empurrar" a produção ou nos modelos de "puxar" a produção.

Alguns autores como Gupta e Boyd (2008) sugerem que a Teoria das Restrições (TOC) reúne qualidades suficientes para ser considerada uma teoria viável à gestão de operações $(O M-$ operational management) em um sentido mais amplo. Para estes autores, a TOC possui prérequisitos suficientes para tal, em virtude das correlações entre a OM e a TOC. Dentre estas correlações, Gupta e Boyd (2008) destacam os seguintes campos de atuação: Estratégias operacionais; Medidas de desempenho; Gerenciamento de processos; Gerenciamento da qualidade e melhoria contínua; Gerenciamento da capacidade e Gestão de estoques.

Neste trabalho realizou-se uma revisão bibliográfica com o objetivo de reunir conhecimentos que permitissem a modelagem e aplicação dos conceitos da TOC em uma empresa de confecções. O Quadro 1 apresenta uma compilação da revisão bibliográfica efetuada ao longo do trabalho.

Quadro 1 - Relação de autores da TOC por área de interesse

\begin{tabular}{|c|c|c|c|}
\hline Autor & Foco da Pesquisa & Área de interesse & Resultados obtidos \\
\hline Kuo et al. (2009) & $\begin{array}{c}\text { Pulmão de tempo (time } \\
\text { buffers) }\end{array}$ & Componentes eletrônicos & Melhora no prazo de entrega \\
\hline Nogueira e Gomes. (2007) & 5 passos de focalização & Vestuário & $\begin{array}{l}\text { Melhora no prazo de entrega e } \\
\text { aumento da produtividade }\end{array}$ \\
\hline Moellmann et al. (2006) & 5 passos de focalização & Automobilístico & Aumento da produtividade \\
\hline $\begin{array}{l}\text { Schragenheim e Ronen } \\
\text { (1991) }\end{array}$ & $\begin{array}{l}\text { Gerenciamento do pulmão } \\
\text { (Buffer management) }\end{array}$ & Teórico & N/A \\
\hline Ho e Li (2006) & Indicadores de desempenho & Teórico & N/A \\
\hline Singh et al. (2006) & 5 passos de focalização & Simulação & Aumento no ganho \\
\hline Sellitto (2005) & Processo de raciocínio (TP) & Saúde Pública & Melhora no atendimento \\
\hline $\begin{array}{l}\text { Mabin e Balderstone } \\
\text { (2003) }\end{array}$ & Aplicações da TOC & Teórico & N/A \\
\hline Umble (1992) & Análise V-A-T & Teórico & N/A \\
\hline Chakravorty (2000) & $\begin{array}{c}\text { Análise V-A-T e Metodologia } \\
\text { TPC }\end{array}$ & Metalurgia & $\begin{array}{c}\text { Melhora dos indicadores } \\
\text { operacionais }\end{array}$ \\
\hline Lockamy (2008) & Análise V-A-T & Cadeia de Suprimentos & N/A \\
\hline Barcaui e Quelhas (2004) & Controle de Projetos & $\begin{array}{l}\text { Gerenciamento de } \\
\text { Projetos }\end{array}$ & N/A \\
\hline Gupta e Boyd, (2008) & Gerenciamento de operações & Pesquisa e ensino & N/A \\
\hline
\end{tabular}

Fonte: Autoria própria (2009)

\section{Modelagem e aplicação dos conceitos da TOC}

Com base na revisão bibliográfica, foram estabelecidas as seguintes etapas para a aplicação da TOC:

- Caracterização do objeto de estudo; 
- Setores produtivos da empresa;

- Definição e apresentação dos produtos;

- Identificação e apresentação dos processos;

- Arranjo físico da confecção;

- Aplicação dos 5 passos de focalização da TOC;

- Análise da aplicação.

\subsection{Caracterização do objeto de estudo}

A empresa, foco deste estudo está situada na cidade de Juiz de Fora, Minas Gerais e iniciou suas atividades em julho de 2008. Atuando no ramo de confecções, produz cuecas em malha e seu principal mercado consumidor são atacadistas e lojistas da cidade de São Paulo, SP. Na época da pesquisa a empresa possuía 17 funcionários e de acordo com a classificação estabelecida pelo SEBRAE (2005) é considerada microempresa.

\subsection{Setores produtivos da empresa}

Os setores produtivos da empresa podem ser divididos da seguinte forma: Setor de Corte; Setor de Costura e Setor de Embalagem. A Figura 2 apresenta em forma de fluxograma o relacionamento entre os três setores e as etapas internas pertencentes a cada um.

Figura 2 - Fluxograma dos setores e etapas da confecção

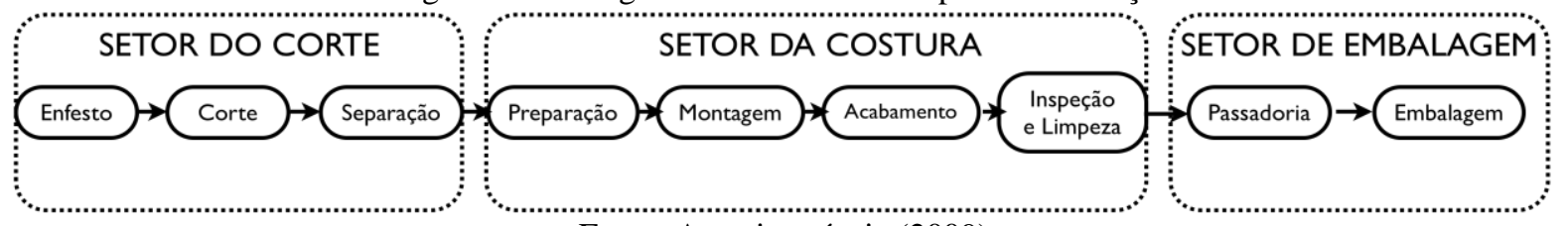

Fonte: Autoria própria (2009)

\subsubsection{Setor do corte}

É o responsável pelo corte do tecido e pelo abastecimento da costura. Para tanto, é necessário que se faça o "encaixe", um programa pré-estabelecido, que leva em conta fatores como: a largura do tecido, medidas dos moldes, distribuição dos tamanhos (grade do pedido) e os recursos disponíveis, tais como o comprimento da mesa de "enfesto". Nesta organização, os encaixes são feitos manualmente. O processo de "enfesto" consiste na disposição do tecido em camadas sobrepostas, que em seguida dá início ao corte do tecido utilizando equipamento de lâmina circular.

Antes de seguirem para o setor de costura, é necessário que as partes de tecido cortadas sejam separadas e agrupadas em pacotes ou lotes. 


\subsubsection{Setor de costura}

Depois de receber os pacotes do setor de corte, estes são distribuídos às operações de produção, seguindo uma sequência definida no planejamento de produção. As seguintes etapas são efetuadas nesta seção: Preparação, Montagem, Acabamento, Inspeção e Limpeza, sendo efetuadas na ordem acima apresentada.

A preparação é responsável por pequenas operações, que devem ser realizadas antes de seguirem para a etapa de montagem, na qual as partes componentes serão unidas. O acabamento, assim como a preparação, executa operações complementares àquelas de montagem. Embora a inspeção deva ser feita durante todo o processo, cabe à etapa de inspeção e limpeza a conferência final da qualidade das costuras, assim como a retirada do excesso de linhas e possíveis defeitos.

\subsubsection{Setor de embalagem}

Finalmente as peças confeccionadas seguem para a Passadoria e Embalagem, onde são passadas, dobradas e envelopadas de acordo com as características do produto. É também na operação de embalagem que são afixados códigos de barra e outros cartões (tags) que sirvam para o controle, promoção ou venda dos produtos.

\subsection{Definição e apresentação dos produtos}

A empresa possui dois modelos de produto, que serão identificados por C1 e C2. A diferença básica entre os dois modelos está no elástico da cintura. No modelo $\mathrm{C} 1$, o elástico é aplicado sobre o tecido e fica aparente lendo-se "MARCA", ou seja, a logomarca da empresa. Enquanto que no modelo C2, o elástico fica embutido e é necessária uma operação a mais para se completar o produto, o rebate do elástico. A Figura 3 ilustra os produto $\mathrm{C} 1$ e $\mathrm{C} 2$ :

Produto $\mathrm{C} 1$

Figura 3 - Ilustração do produto C1 e C2

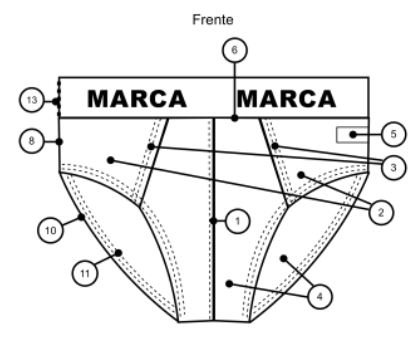

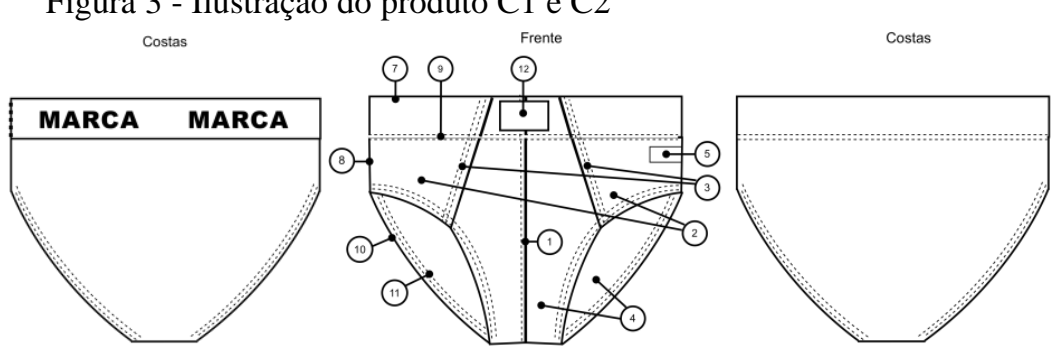

Fonte: Autoria própria (2009)

Produto C2 
A prática comum de comercialização de produtos de moda íntima e meias é feita na forma de dúzias desses produtos. Para se obter um "mix" de cores que agrade aos consumidores a empresa pesquisa em publicações do setor, sites da internet, fornecedores têxteis e clientes, a fim de oferecer combinações com as tendências da estação.

As cores exercem uma grande influência na comercialização dos produtos, elas mudam de acordo com as coleções, tais como os produtos de moda, seguem tendências e precisam ser renovados periodicamente, exigindo das empresas pesquisa e acompanhamento constante. A empresa estudada optou por trabalhar com nove cores de tendência, das quais três são repetidas para se obter uma dúzia.

\subsection{Identificação e apresentação dos processos}

Os processos envolvidos na fabricação dos produtos C1 e C2 possuem algumas operações em comum e outras exclusivas a cada produto, como se pode observar na figura 4. Os processos foram chamados de "P" seguidos de um número e são descritos a seguir.

Primeiramente são descritos os processos comuns aos produtos $\mathrm{C} 1$ e $\mathrm{C} 2$ :

- P1 - É a primeira operação e consiste em unir a frente e o forro através da passagem de um viés, essa operação acontece em uma máquina de duas agulhas adaptada para esse processo.

- P2 - A segunda operação une duas partes laterais em malha canelada diferente da meiamalha usada nas demais partes, isso se dá com a intenção de criar um detalhe diferenciado ao produto. É utilizada uma máquina overloque normal.

- P3 - É a passagem de dois pespontos em uma máquina de duas agulhas.

- P4 - Essa operação une a frente com as costas utilizando máquina overloque normal.

- P5 - É a operação que fecha uma das laterais juntamente com a aplicação de uma etiqueta de instruções de cuidados em uma máquina overloque normal.

- P8 - Fecha o segundo lado em máquina overloque normal.

- P10 - Aplica o elástico na perna e utiliza uma máquina overloque adaptada a esse propósito.

- P11 - Rebate o elástico da perna em uma máquina de duas agulhas adaptada.

- A seguir, são descritos os processos exclusivos para C1:

- P6 - Esta operação é a aplicação do elástico de cintura personalizado em uma máquina de duas agulhas refiladeira.

- P13 - É a operação de reforço da costura lateral do elástico através de uma costura realizada em máquina travete.

A Figura 4 ilustra o fluxograma de montagem para ambos os produtos, na parte superior encontram-se o fluxo para $\mathrm{C} 1$ e na parte inferior o fluxo para $\mathrm{C} 2$ : 
Figura 4 - Fluxograma de montagem do produto $\mathrm{C} 1$ e C2

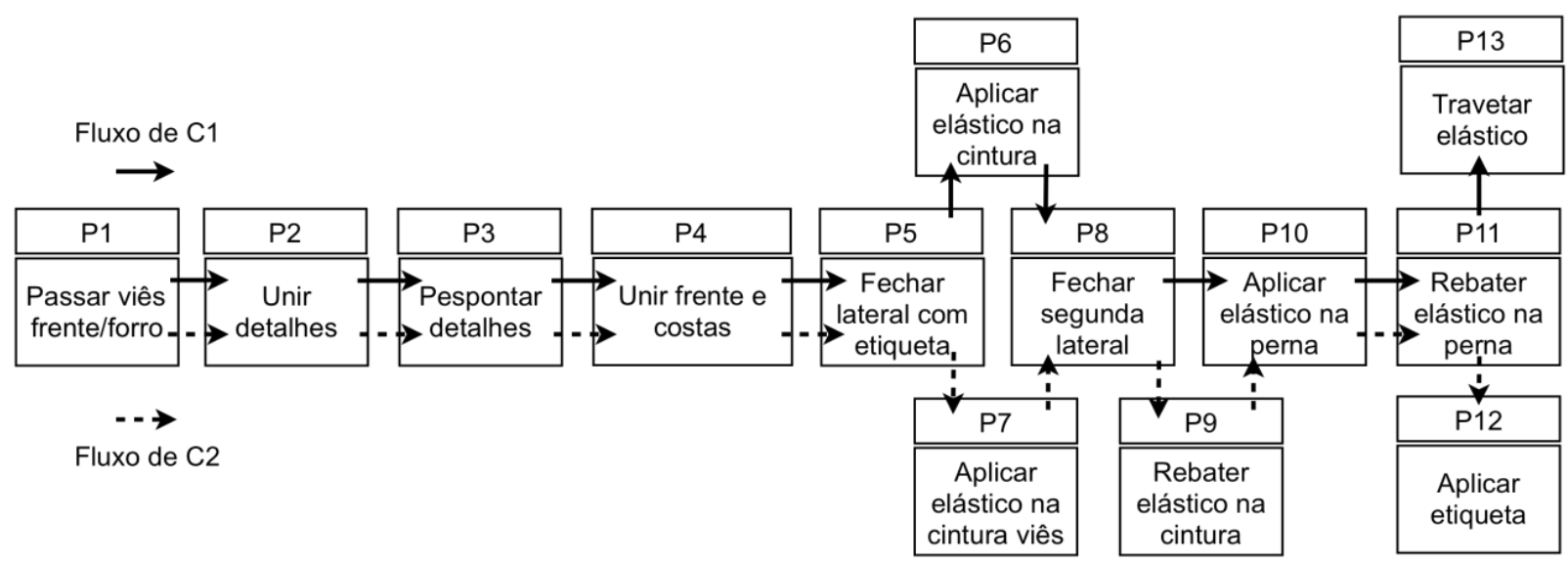

Fonte: Autoria própria (2009)

Processos exclusivos para $\mathrm{C} 2$ :

- P7 - Consiste em aplicar o elástico na cintura em uma máquina overloque adaptada para esta função.

- P9 - É a operação de rebater o elástico deixando-o embutido, é feita em uma máquina de duas agulhas adaptada.

- P12 - É a operação de aplicar uma etiqueta externa com a marca do produto, é feita em uma máquina de costura reta.

\subsubsection{Insumos utilizados na produção}

Todo processo fabril caracteriza-se pela transformação de matéria-prima em produtos acabados. Nos processos de industrialização os insumos representam uma grande fatia do preço de venda dos produtos. O Quadro 2 apresenta de forma agrupada, os insumos utilizados para a confecção dos produtos em estudo.

Quadro 2 - Insumos necessários para a produção dos produtos C1 e C2

\begin{tabular}{cccc}
\hline Descrição & Grupo & $\begin{array}{c}\text { Participação no custo total } \\
\text { da materia-prima de C1 }\end{array}$ & $\begin{array}{c}\text { Participação no custo total } \\
\text { da matéria-prima de C2 }\end{array}$ \\
\hline $\begin{array}{c}\text { Meia-malha } \\
\text { Malha canelada }\end{array}$ & Malha & $41 \%$ & $64 \%$ \\
\hline Fio de poliéster & Fio de costura & $2 \%$ & $3 \%$ \\
\hline $\begin{array}{c}\text { Etiqueta de composição } \\
\text { Elástico personalizado } \\
\text { Elástico de perna }\end{array}$ & Aviamentos & $48 \%$ & $21 \%$ \\
\hline $\begin{array}{c}\text { Cartela de apresentação } \\
\text { Saco pvc personalizado } \\
\text { Caixa de papelão } \\
\text { Fita adesiva }\end{array}$ & Embalagem & $9 \%$ & $12 \%$ \\
Fita de amarração & & $100 \%$ & $100 \%$ \\
\hline
\end{tabular}

Fonte: Autoria própria (2009) 
Embora semelhantes, os produtos C1 e C2 apresentam uma composição de custos bem diferentes como observados nas colunas contendo a participação no custo total da matéria-prima, os valores indicam em percentagem o peso que cada item exerce sobre os custos totais. $\mathrm{O}$ gráfico 1 apresenta de maneira clara uma comparação da participação por grupo de custos entre os produtos $\mathrm{C} 1$ e C2:

Gráfico 1 - Comparativo na participação por grupos de insumos entre os produtos C1 e C2

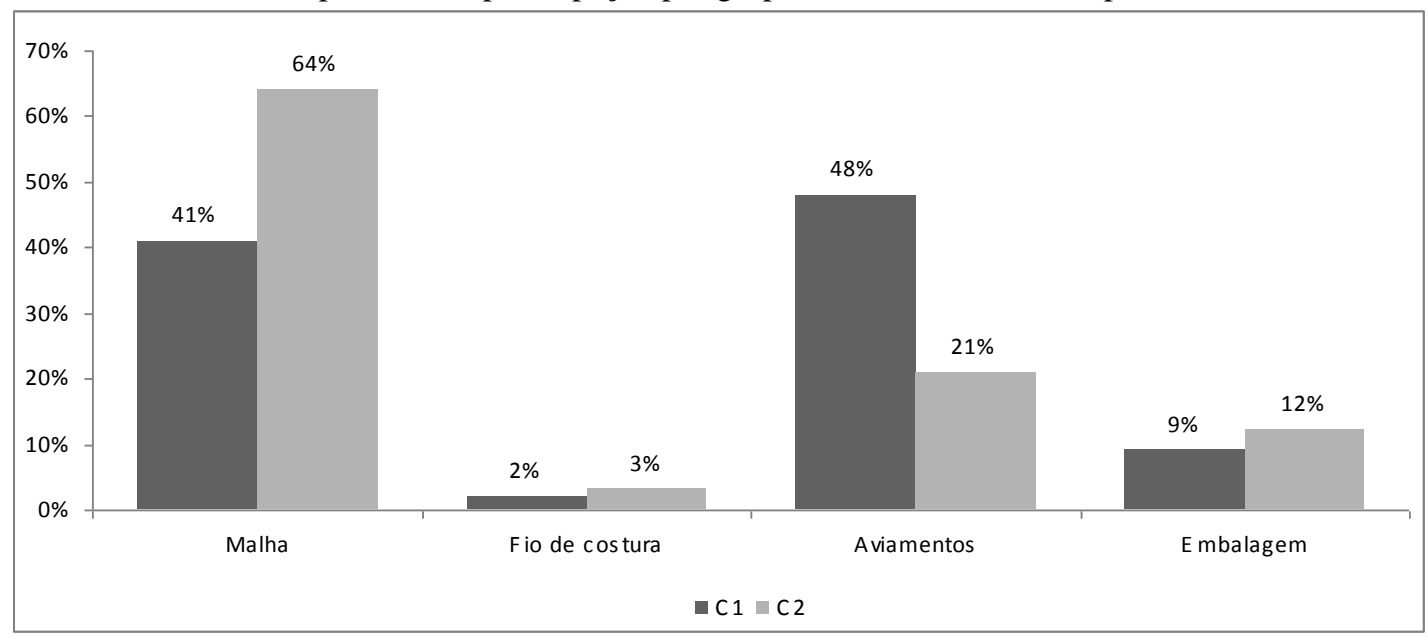

Fonte: Autoria própria (2009)

Observa-se que o produto $\mathrm{C} 1$ apresenta como principal custo o grupo dos aviamentos, representando $48 \%$, isso se deve ao valor do item elástico personalizado cujo custo é o mais representativo. Já o produto C2 tem o grupo malha com $64 \%$, como seu principal custo dentre os insumos. De maneira global nota-se que mesmo $\mathrm{C} 1$ tendo os aviamentos como principal grupo de custos, o peso da malha ainda é bastante expressivo $41 \%$, fazendo desse item o mais representativo dentre os insumos utilizados como um todo. Por essa razão a malha é responsável por gerar vantagem competitiva em termos de custos com a concorrência.

Para a confecção dos produtos C1 e C2 são necessários dois tipos de malhas diferentes, que são: meia-malha e malha canelada. A meia-malha é a principal malha utilizada representando $80 \%$ do total consumido, enquanto a malha canelada representa os outros $20 \%$, sendo utilizada apenas para compor o detalhe lateral de ambos os produtos.

A forma encontrada pela empresa para diminuir os custos com a malha foi incorporar através da terceirização, os processos de tecelagem e tinturaria.

\subsection{Arranjo físico da confecção}

Os processos são distribuídos na planta de produção segundo a seguinte configuração: o setor de corte possui uma operadora e uma máquina de corte que realizam todos os processos necessários para obtenção das partes componentes; a seção de costura possui 12 operadoras e conta 
com 14 máquinas utilizadas de acordo com o modelo a ser produzido; a seção de acabamento possui 2 operadoras que desenvolvem todo o trabalho manualmente; e uma supervisora de produção que auxilia na distribuição e acompanhamento da produção.

A Figura 5 apresenta, de forma esquemática, o arranjo físico do sistema de produção da organização em foco.

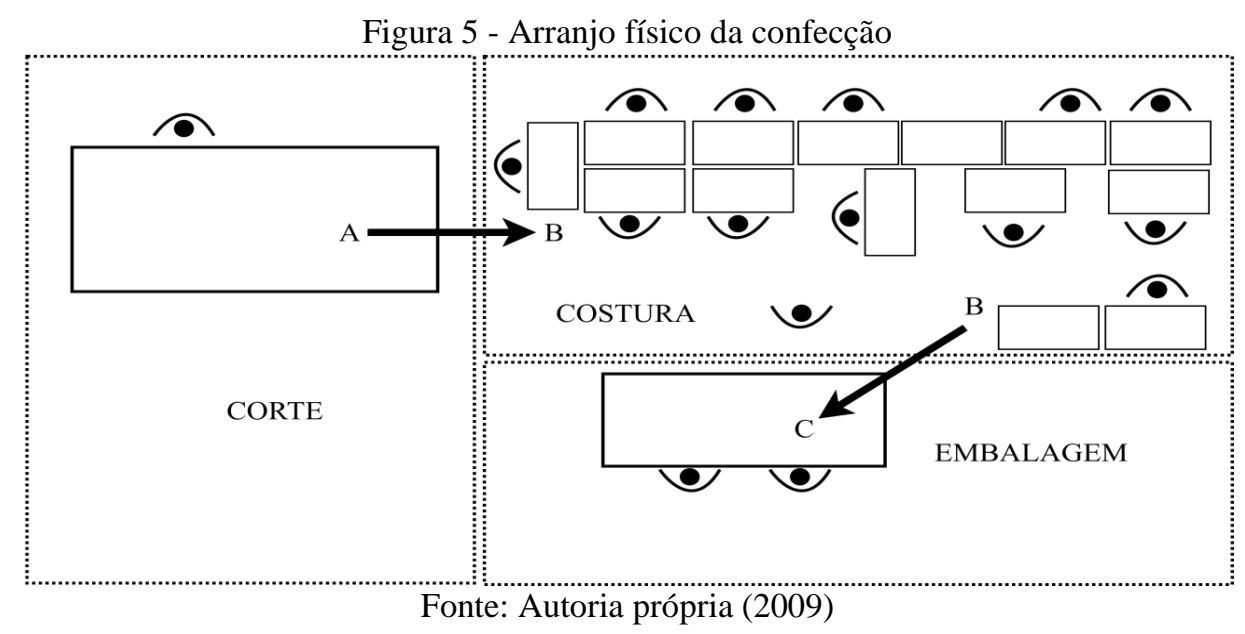

O fluxo de produção inicia-se no corte (A), segue para a costura (B) e termina na embalagem (C), como destacado na figura 5.

Devido ao maior número de máquinas na seção de costura, é apresentada na tabela 1 a distribuição de máquinas por processo e modelos de produto.

Os processos que fazem parte de cada produto foram assinalados com um x nas colunas $\mathrm{C} 1 \mathrm{e}$ $\mathrm{C} 2$.

Tabela 1 - Processos e máquinas utilizadas, no setor de costura, para a fabricação de C1 e C2

\begin{tabular}{cccccc}
\hline Processo & Descrição da operação & Máquinas & Tipo da Máquina & C1 & C2 \\
\hline P1 & Passar o viés frente/forro & M1 & 2 agulhas adaptada & X & X \\
P2 & Unir detalhes & M2 e M14 & Overloque & X & X \\
P3 & Pespontar detalhes & M3 & 2 agulhas & X & X \\
P4 & Unir frente e costas & M4 & Overloque & X & X \\
P5 & Fechar lateral com etiqueta & M5 & Overloque & X & X \\
P6 & Aplicar elástico na cintura & M6 & Refiladeira & X & \\
P7 & Aplicar elástico cintura viés & M7 & Overloque adaptada & & X \\
P8 & Fechar segunda lateral & M8 & Overloque & X & X \\
P9 & Rebater elástico da cintura & M9 & 2 agulhas adaptada & & X \\
P10 & Aplicar elástico na perna & M10 & Overloque adaptada & X & X \\
P11 & Rebater elástico da perna & M11 & 2 agulhas adaptada & X & X \\
P12 & Aplicar etiqueta & M12 & Reta & & X \\
P13 & Travetar elástico & M13 & Travete & X & \\
\hline
\end{tabular}

Fonte: Autoria própria (2009) 


\subsubsection{Detalhamento do fluxo de produção}

O fluxo de produção inicia-se com a chegada da malha no corte. Entretanto, para assegurar que as quantidades nas cores certas irão terminar o processo a ponto de serem expedidas é necessário atender a alguns padrões pré-estabelecidos. Sendo assim, o corte trabalha com dois tamanhos de lotes, lote 1 para cores únicas e lote 2 para cores que se repetem, obedecendo a seguinte distribuição:

- Lote 1 - Total de 6 dúzias distribuídas no tamanho P com 1 dúzia, M com 2 dúzias, G com 2 dúzias e GG com 1 dúzia;

- Lote 2 - Total de 12 dúzias distribuídas no tamanho P com 2 dúzias, M com 4 dúzias, G com 4 dúzias e GG com 2 dúzias.

Os produtos completam kits que são vendidos em dúzias. As cores básicas como, azul, preto e branco se repetem fazendo parte do lote 2, as demais fazem parte do lote 1 . Com base na carteira de pedidos da fábrica e o nível de estoque dos produtos acabados, decide-se por qual produto começar.

Estabelece-se a ordem dos kits a serem produzidos, ou seja, se o kit é composto das cores 1, 2 e 3, a ordem de corte obedecerá a essa sequência. Iniciam-se os processos de encaixe e corte dos tecidos.

Assim que o primeiro tamanho de uma cor é completado, segue para o setor de costura. Ressaltando-se que o lote de transferência não é igual ao de produção.

Uma vez transferido para o setor de costura, a sequência para análise do fluxo de produção irá variar de acordo com o produto.

A Figura 6 apresenta o fluxo do produto C1, através das máquinas localizadas na costura:

Figura 6 - Fluxo do produto $\mathrm{C} 1$ na costura

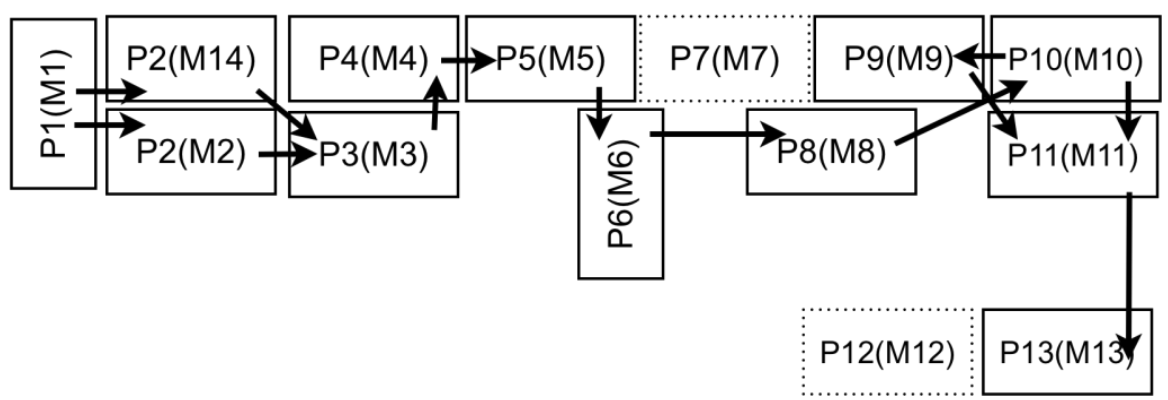

Fonte: Autoria própria (2009)

O fluxo inicia-se na máquina M1, onde é passado o viés unindo a frente e o forro, segue para a máquina M2 ou M14, onde são aplicados os detalhes laterais. Logo após segue para M3 onde são pespontados esses detalhes. Na máquina M4 são unidas frente e costas. A máquina M5 fecha o 
primeiro lado afixando uma etiqueta de composição, a máquina M6 aplica o elástico da cintura, M8 fecha o segundo lado, M10 aplica o elástico das pernas. Nesse ponto podem seguir para M9 ou M11 onde são rebatidos os elásticos da perna e finalmente seguem para M13 onde é feita uma costura para reforço da lateral do elástico. A Figura 7 apresenta o fluxo do produto $\mathrm{C} 2$, através das máquinas localizadas na costura:

Figura 7 - Fluxo do produto C2 na montagem

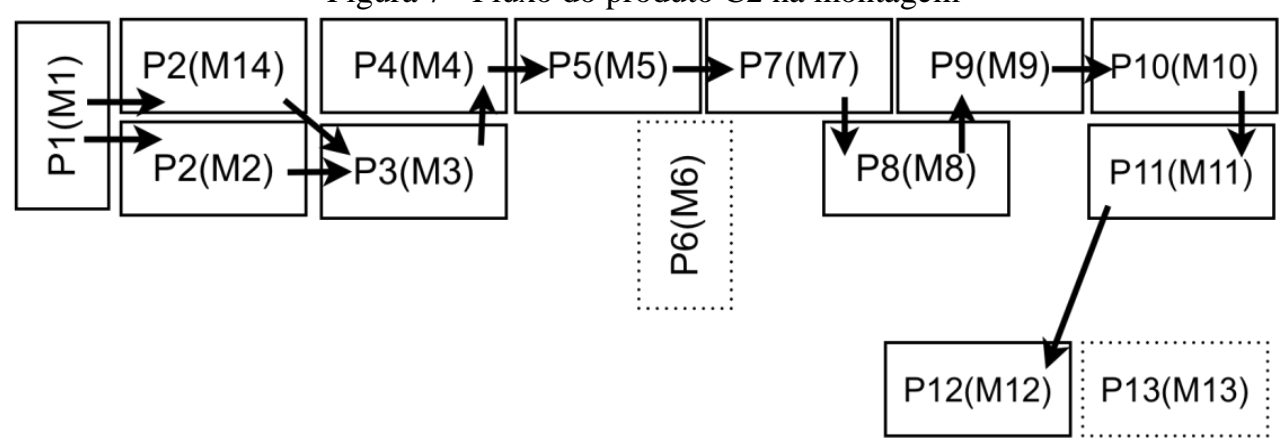

Fonte: Autoria própria (2009)

Assim como no caso do produto $\mathrm{C} 1$ este fluxo também se inicia na máquina $\mathrm{M} 1$, onde é passado o viés unindo a frente e o forro, segue para a máquina M2 ou M14, onde são aplicados os detalhes laterais, seguindo para M3 onde são pespontados esses detalhes. Na máquina M4, são unidas frente e costas. A máquina M5 fecha o primeiro lado afixando uma etiqueta de composição. A partir desse ponto nota-se a diferença no fluxo do processo entre os produtos $\mathrm{C} 1$ e $\mathrm{C} 2$. O produto C2 irá para a máquina M7 onde é aplicado o elástico na cintura que ficará embutido, logo após segue para M8 onde é fechada a segunda lateral e segue para M9 rebater o elástico da cintura, na máquina M10 é aplicado o elástico da perna e em M11 o elástico é rebatido, seguindo para M12 onde é aplicada a etiqueta externa e por fim completa-se a montagem do produto $\mathrm{C} 2$.

Terminadas as operações de montagem dos produtos, Iniciam-se as operações de embalagem. Fazem parte desse processo a limpeza e inspeção, no qual são retirados os excessos de linhas e verificados possíveis defeitos, além de dobrar e embalar.

\section{Aplicação dos cinco passos de focalização da TOC}

De acordo com Goldratt (1993) os cinco passos de focalização são os seguintes:

- Identificar a restrição do sistema;

- Decidir como explorar a restrição do sistema. Analisar a forma mais eficiente de se explorar o recurso com restrição de capacidade (RRC).

- Subordinar todo o sistema às decisões acima;

- Elevar as restrições do sistema (aumentar a capacidade do recurso gargalo);

- Se a restrição tiver sido quebrada em um dos passos anteriores, retornar ao passo 1. 
Não deixar a inércia se transformar na restrição do sistema.

\subsection{Identificação do gargalo do sistema}

O primeiro passo foi identificar a restrição para a empresa foco desse estudo. Para a TOC uma restrição é tudo aquilo que impede um sistema de obter um desempenho superior. No caso desse estudo a restrição é o que limita a produção dos produtos $\mathrm{C} 1$ e C2.

Segundo Goldratt (1992) não é necessário que se calcule individualmente toda a capacidade disponível dos recursos do sistema, bastando apenas observar no chão-de-fábrica em qual local estão as maiores pilhas de estoques esperando para processamento, a frente dessas possivelmente estará o gargalo. $\mathrm{O}$ autor sugere que a partir da escolha desse recurso, parta-se para o segundo passo o de se explorar o gargalo. A partir desse momento, se este não for o verdadeiro gargalo rapidamente outro recurso chamará atenção apresentando outra pilha a sua frente e assim o foco passaria para este, até que não restem dúvidas sobre o verdadeiro gargalo. Seguindo esta lógica foi possível reconhecer o setor de costura como o responsável pelo gargalo do sistema, pois à entrada do setor encontravam-se as maiores pilhas de material em processo.

A Figura 8 ilustra a identificação do setor da costura como sendo o gargalo dentro do sistema de produção.

Figura 8 - Identificação do setor de costura como gargalo do sistema

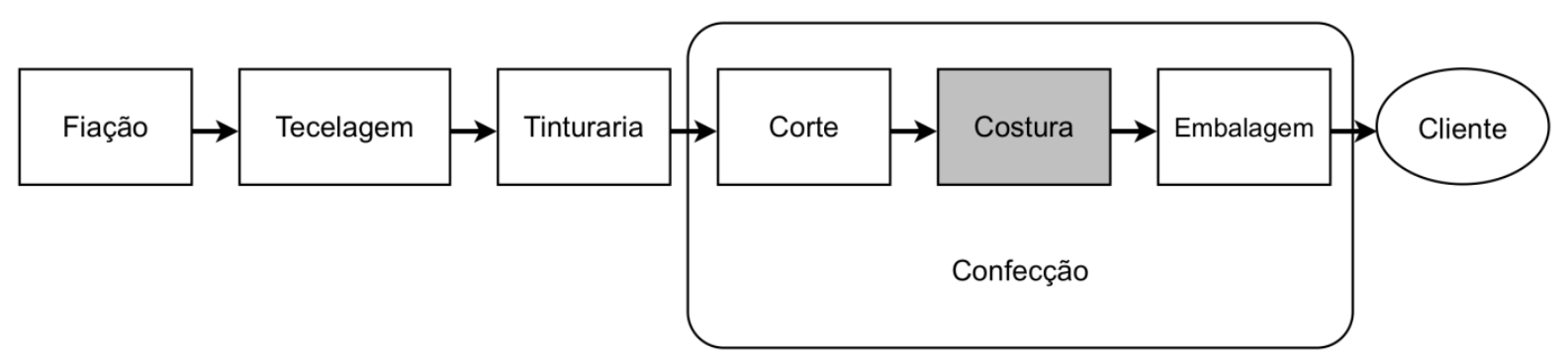

Fonte: Autoria própria (2009)

A identificação do setor de costura como a restrição do sistema indica que os outros elos envolvidos no processo possuem capacidade produtiva superiores ao seu. Neste ponto, foi necessário se obter com precisão os dados sobre a capacidade de produção de cada processo do setor de costura, a fim de se identificar o gargalo entre as operações e com isso conhecer a capacidade produtiva de todo o setor.

Para se conhecer a capacidade de produção do sistema foi efetuado um levantamento dos tempos de cada operação, através da cronometragem. Neste levantamento utilizou-se um cronômetro com precisão centesimal, da marca Oregon Scientific, modelo SL928M com capacidade de armazenamento de 500 tomadas de tempo.

As aferições dos tempos de processamento foram coletadas durante uma semana no período de 01/02/2010 à 5/02/2010, em horários alternados de acordo com a técnica de cronometragem e 
padrões difundidos no curso de supervisor de confecções oferecido pelo SENAI (GUIMARÃES, 2004). As tomadas de tempo ocorreram em horários aleatórios com o objetivo de compensar variações ao longo da jornada de trabalho, ao final foi possível criar um banco de dados com mais de duzentas tomadas de tempo.

Em acordo com Guimarães (2004), para realizar a cronometragem é necessário que se identifique o ciclo da operação, que começa com o inicio da atividade e termina com o inicio da atividade subsequente, sendo assim o cronômetro é disparado quando a operadora apanha a primeira peça e para quando ela apanha a segunda, já sendo disparado novamente. Esse procedimento é repetido até que se completem dez ciclos. No momento da tomada de tempos, são observados o ritmo de trabalho e o fluxo de produção, que não deve ser interrompido até que se completem os dez ciclos. Os tempos são então somados e divididos por dez, encontrando-se a média. Para o uso da simulação foram utilizadas as médias dos tempos encontrados na cronometragem. Observa-se que esta orientação está em acordo com as recomendações reportadas em Da Silva (2009), que realça a diferença entre tempos improdutivos e tempos de operação.

A Tabela 2 apresenta o resultado com as médias dos tempos encontrados para o produto $\mathrm{C} 1$ e C2. Observa-se que alguns operadores executam tarefas diferentes de acordo com o modelo em produção. O operador $\mathrm{O} 8$ é responsável pela operação $\mathrm{P} 2$ quando se produz $\mathrm{C} 1$ e é responsável pela operação P9 quando se produz C2. Assim também é o caso de O6 que é responsável pela operação P6 quando se produz C1 e pela operação P7 quando se produz C2. O operador O11 é responsável pela operação P13 quando se produz C1 e P12 quando se produz C2.

Tabela 2 - Tempo padrão das operações

\begin{tabular}{cccccc}
\hline & \multicolumn{2}{c}{ Produto C1 } & \multicolumn{2}{c}{ Produto C2 } \\
\hline Processo & Máquinas & Operador & Tempo* & Operador & Tempo* \\
P1 & M1 & O1 & 6,11 & O1 & 6,11 \\
P2 & M2 & O2 e O8 & 9,78 & O2 & 19,55 \\
P3 & M3 & O3 & 9,67 & O3 & 9,67 \\
P4 & M4 & O4 & 12,13 & O4 & 12,13 \\
P5 & M5 & O5 & 9,92 & O5 & 9,92 \\
P6 & M6 & O6 & 6,91 & & \\
P7 & M7 & & & O6 & 6,06 \\
P8 & M8 & O7 & 9,38 & O7 & 9,38 \\
P9 & M9 & & & O8 & 9,28 \\
P10 & M10 & O9 & 10,85 & O9 & 10,85 \\
P11 & M11 & O10 & 13,92 & O10 & 13,92 \\
P12 & M12 & & & O11 & 9,62 \\
P13 & M13 & O11 & 5,8 & & \\
\hline
\end{tabular}

* Tempo expresso em segundos

Fonte: Autoria própria 
De acordo com a Tabela 2 para o produto $\mathrm{C} 1$ a operação com o maior tempo de processamento é P11 e para C2 o maior tempo é o da operação P2. Ou seja, dependendo do produto em processo tem-se uma restrição diferente. Para que se possa encontrar a restrição do sistema é necessário primeiramente conhecer a demanda individual para cada produto e o tempo disponível de cada recurso. O tempo disponível para os recursos é a jornada de trabalho da fábrica que é de 8:30h (oito horas e trinta minutos) por dia, para facilitar a simulação será usado o tempo em segundos, no caso 30600 segundos.

A demanda pelos produtos, de acordo com o histórico de vendas da empresa, é de 1200 peças do produto $\mathrm{C} 1$ e 1200 do produto C2 por dia. Com base nestas informações pode-se calcular a utilização dos recursos para atenderem a demanda diária do mercado.

A Tabela 3 apresenta os cálculos e a utilização dos recursos necessários para se atender à demanda de 1200 unidades por produto. Como se pode observar, o processo com maior restrição no sistema é P2, visto que C1 necessita de 9,78 segundos por produto, precisa trabalhar 11.736 segundos e C2 utilizando 19,55 segundos precisa de mais 23.460 segundos. A soma do tempo total para atender a demanda dos dois produtos é de 35.196 segundos, ou seja, 15\% a mais que a capacidade de P2 que é de 30600 segundos. Dessa forma não é possível atender toda a demanda prevista para o mercado, pois a utilização de P2 ultrapassa os 100\%. P2 é o gargalo do sistema.

Tabela 3- Simulação da capacidade necessária para atender a demanda de 1200 unidades por produto

\begin{tabular}{|c|c|c|c|c|c|c|}
\hline \multirow[b]{2}{*}{ Processo } & \multicolumn{2}{|c|}{ Tempo* por processo } & \multirow{2}{*}{$\frac{\begin{array}{c}\text { Tempo } \\
\text { disponível }\end{array}}{\text { Dia* }}$} & \multicolumn{2}{|c|}{$\begin{array}{c}\text { Tempo necessário para atender a } 1200 \\
\text { unid. por produto }\end{array}$} & \multirow{2}{*}{$\frac{\text { Utilização }}{\%}$} \\
\hline & $\mathrm{C} 1$ & $\mathrm{C} 2$ & & $\mathrm{C} 1$ & $\mathrm{C} 2$ & \\
\hline $\mathrm{P} 1$ & 6,11 & 6,11 & 30600 & 7332 & 7332 & $48 \%$ \\
\hline $\mathrm{P} 2$ & 9,78 & 19,55 & 30600 & 11736 & 23460 & $115 \%$ \\
\hline P3 & 9,67 & 9,67 & 30600 & 11604 & 11604 & $76 \%$ \\
\hline $\mathrm{P} 4$ & 12,13 & 12,13 & 30600 & 14556 & 14556 & $95 \%$ \\
\hline P5 & 9,92 & 9,92 & 30600 & 11904 & 11904 & $78 \%$ \\
\hline P6 & 6,91 & & 30600 & 8292 & & $27 \%$ \\
\hline P7 & & 6,06 & 30600 & & 7272 & $24 \%$ \\
\hline P8 & 9,38 & 9,38 & 30600 & 11256 & 11256 & $74 \%$ \\
\hline P9 & & 9,28 & 30600 & & 11136 & $36 \%$ \\
\hline P10 & 10,85 & 10,85 & 30600 & 13020 & 13020 & $85 \%$ \\
\hline P11 & 13,92 & 13,92 & 30600 & 16704 & 16704 & $109 \%$ \\
\hline $\mathrm{P} 12$ & & 9,62 & 30600 & & 11544 & $38 \%$ \\
\hline P13 & 5,80 & & 30600 & 6960 & & $23 \%$ \\
\hline
\end{tabular}

* Tempo expresso em segundos

Fonte: Autoria própria

\subsection{Explorando o gargalo do sistema}

Uma vez identificado o gargalo é preciso explorá-lo. Explorar significa aproveitar todo o tempo disponível do recurso, o que significa assegurar que o recurso deva fazer apenas o que se 
espera que ele faça. Para se ter certeza de que isso acontecerá, a TOC propõe que se crie uma programação da produção baseada na metodologia Tambor-Pulmão-Corda (TPC) (GOLDRATT \& FOX,1992). A Figura 9 propõe o esquema para o planejamento e controle da produção da TOC para o sistema de produção da empresa.

A Figura 9 apresenta os componentes necessários para a programação TPC, que são: O tambor (gargalo) como sendo o setor da costura; O pulmão de tempo localizando-se à entrada do setor da costura; E a corda que amarra o tambor ao início do processo, ou seja, liberação de matériaprima na fiação.

Figura 9 - Esquema para implantação da metodologia TPC

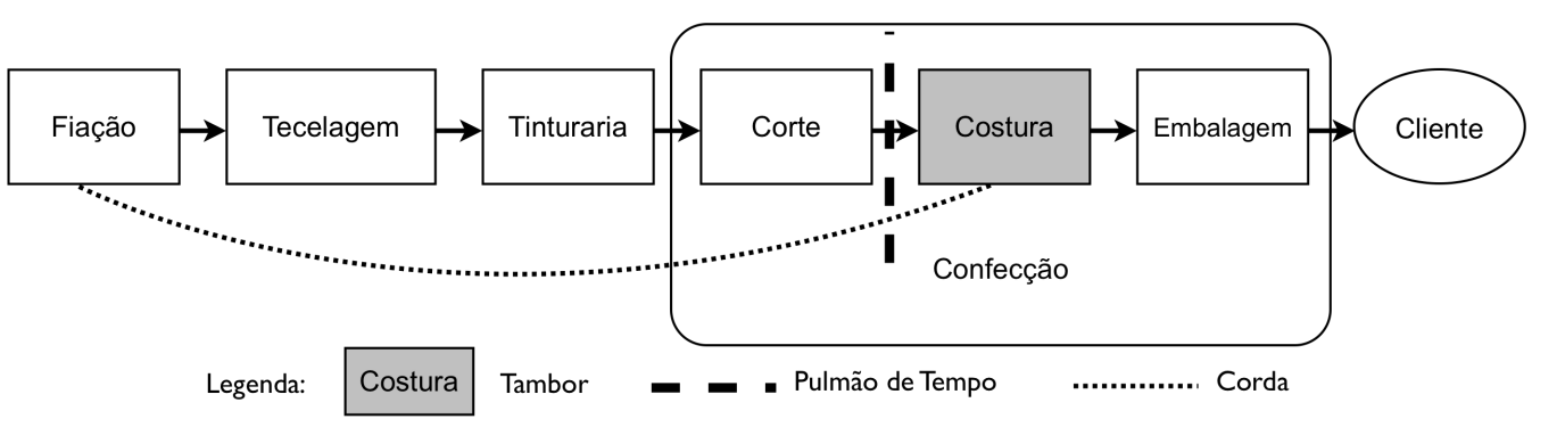

Fonte: Autoria própria (2009)

O tambor por ser o gargalo do sistema, é quem dita o ritmo da produção e define o ganho (throughput) da empresa. Para assegurar que o gargalo não pare por falta de alimentação é criado um pulmão de tempo. O objetivo deste pulmão é proteger o gargalo tornando possível à gerência o monitoramento dos pedidos a serem processados, permitindo serem tomadas providências quando os níveis de estoque não estiverem de acordo com o programa. A corda limita a entrada de matériaprima no sistema fazendo com que seja obedecida a capacidade de processamento do tambor, com isso regula os níveis de estoque em processo.

Para operacionalização do programa TPC na prática, é necessário definir os volumes de produção a serem processados pelo gargalo (tambor) e o tamanho do estoque de segurança (pulmão) que se pretende trabalhar e a quantidade de matéria-prima a ser liberada (corda) para o sistema. Para se chegar a esses valores é preciso quantificar o volume de produtos processados pelo gargalo.

Uma vez conhecida a capacidade de produção para o produto $\mathrm{C} 1$ e $\mathrm{C} 2$, definiu-se o volume de matéria-prima a ser liberada (corda) para o sistema e dessa forma controlar os níveis de inventário (estoque) em processo. Foi possível também definir qual o tamanho do pulmão, evitando possíveis paradas. O tamanho do pulmão de tempo deve ser o suficiente para que se resolvam problemas de interrupção no abastecimento de produtos para o gargalo.

Para a TOC, explorar o gargalo significa gerar o maior ganho possível através do recurso com restrição. No caso de dois ou mais produtos competindo pelo mesmo recurso e cada um deles 
gerando ganhos diferentes é preciso optar pela fabricação do produto que gere maior ganho para a empresa. A Tabela 4 apresenta o ganho gerado por unidade do produto $\mathrm{C} 1$ e C2.

Tabela 4 - Ganho gerado pelo produto C1 e C2

\begin{tabular}{cccc}
\hline Produto & Preço de Venda* & Custo da Matéria-prima & Ganho \\
\hline $\mathrm{C} 1$ & $\mathrm{R} \$ 1,92$ & $\mathrm{R} \$ 1,11$ & $\mathrm{R} \$ 0,81$ \\
$\mathrm{C} 2$ & $\mathrm{R} \$ 1,73$ & $\mathrm{R} \$ 0,86$ & $\mathrm{R} \$ 0,87$ \\
\hline
\end{tabular}

*valores por unidade

Fonte: Autoria própria (2009)

Uma vez conhecido o ganho gerado por cada produto é preciso calcular quanto o recurso gargalo pode gerar por tempo de utilização. No caso do produto $\mathrm{C} 1$ são utilizados 9,78 segundos de P2 o que significa que a cada segundo P2 gera ( $\mathrm{R} \$ 0,81 / 9,78) \mathrm{R} \$ 0,08$, enquanto $\mathrm{C} 2$ que utiliza 19,55 segundos gera $(\mathrm{R} \$ 0,87 / 19,55) \mathrm{R} \$ 0,04$ por segundo, ou seja, a metade do ganho de $\mathrm{C} 1$. Dessa forma, mesmo $\mathrm{C} 2$ gerando um ganho por produto maior que $\mathrm{C} 1$, quando analisado do ponto de vista da utilização do tempo do gargalo, $\mathrm{C} 1$ gera maior ganho para todo o sistema.

A Tabela 5 apresenta a demanda factível de ser atendida pelo recurso P2. Adequando-se a produção à capacidade do gargalo e priorizando a produção de $\mathrm{C} 1$, a empresa poderia atender a uma demanda de 1200 peças de $\mathrm{C} 1$ e 965 peças de C2.

Tabela 5 - Utilização dos recursos com $100 \%$ de utilização do gargalo

\begin{tabular}{|c|c|c|c|c|c|c|}
\hline \multirow[b]{2}{*}{ Processo } & \multicolumn{2}{|c|}{ Tempo por processo } & \multirow{2}{*}{$\begin{array}{c}\begin{array}{c}\text { Tempo } \\
\text { disponível }\end{array} \\
\text { Dia* }^{*}\end{array}$} & \multicolumn{2}{|c|}{$\begin{array}{l}\text { Tempo necessário para atender } 1200 \\
\text { unid. de } \mathrm{C} 1 \text { e } 965 \text { unid. de } \mathrm{C} 2\end{array}$} & \multirow{2}{*}{$\frac{\text { Utilização }}{\%}$} \\
\hline & $\mathrm{C} 1$ & $\mathrm{C} 2$ & & $\mathrm{C} 1=1200$ & $\mathrm{C} 2=965$ & \\
\hline $\mathrm{P} 1$ & 6,11 & 6,11 & 30600 & 7332 & 5896 & $43 \%$ \\
\hline $\mathrm{P} 2$ & 9,78 & 19,55 & 30600 & 11730 & 18866 & $100 \%$ \\
\hline P3 & 9,67 & 9,67 & 30600 & 11604 & 9332 & $68 \%$ \\
\hline $\mathrm{P} 4$ & 12,13 & 12,13 & 30600 & 14556 & 11705 & $86 \%$ \\
\hline P5 & 9,92 & 9,92 & 30600 & 11904 & 9573 & $70 \%$ \\
\hline P6 & 6,91 & & 30600 & 8292 & & $27 \%$ \\
\hline P7 & & 6,06 & 30600 & & 5848 & $19 \%$ \\
\hline P8 & 9,38 & 9,38 & 30600 & 11256 & 9052 & $66 \%$ \\
\hline P9 & & 9,28 & 30600 & & 8955 & $29 \%$ \\
\hline P10 & 10,85 & 10,85 & 30600 & 13020 & 10470 & $77 \%$ \\
\hline P11 & 13,92 & 13,92 & 30600 & 16704 & 13433 & $98 \%$ \\
\hline $\mathrm{P} 12$ & & 9,62 & 30600 & & 9283 & $30 \%$ \\
\hline P13 & 5,8 & & 30600 & 6960 & & $23 \%$ \\
\hline
\end{tabular}

* Tempo expresso em segundos

Fonte: Autoria própria 


\subsection{Subordinar todo o sistema ao gargalo}

A etapa de subordinação pode ser vista como uma consequência da aplicação da metodologia de programação da produção TPC. Subordinar nesse caso, significa fazer com que todos os recursos não-gargalo sigam a programação feita para o recurso gargalo.

Nesse ponto, a empresa precisou mudar a cultura, na qual o ótimo global não é igual à soma dos ótimos locais e sim resultado do gerenciamento da restrição do sistema. Para isso, deve deixar de buscar a eficiência por setores, baseada nas premissas da contabilidade de custos, medindo a produtividade isolada de cada setor. O conceito baseado em ótimos locais faz com que os gestores procurem manter seu pessoal o tempo todo ocupado fazendo com que os níveis de estoque cresçam e prejudiquem o desempenho global da empresa. A principal função exercida pela corda na programação TPC é evitar esse impulso de manter as pessoas ocupadas na produção de itens que irão para o estoque ou que não foram vendidos ainda. A corda só libera os materiais que serão processados pelo gargalo de acordo com a programação que foi feita para ele, dessa forma os outros setores ficam limitados, ou seja, subordinados a essas quantidades. Assim que o material é liberado os setores não-gargalo poderão trabalhar imediatamente nesses itens, agilizando o tempo de atravessamento (lead time) pela fábrica.

A capacidade encontrada disponível para atender a demanda foi de 1200 peças de C1 e 965 peças de C2. Assim sendo, a programação da produção tomou como base para seu planejamento esses valores. Na prática isso significou liberar material suficiente para que se atenda a estes pedidos, e o pulmão de tempo ter um tamanho suficiente para proteger o gargalo e evitar a falta de material.

\subsection{Elevar a restrição do sistema}

A etapa de elevar a restrição do sistema deve levar em conta dois aspectos importantes: a capacidade interna do sistema e o volume de vendas.

Como a TOC preconiza, uma restrição pode ser uma limitação física, como um gargalo da produção ou uma restrição política, como lotes mínimos para a venda de produtos ou ainda, valores mínimos de faturamento que podem fazer com que clientes deixem de comprar.

No caso da empresa foco desse estudo a restrição encontra-se na capacidade interna de produção e não no mercado, uma vez que sua produção é inferior a esta demanda. A Tabela 6 apresenta a nova configuração do sistema de produção, após a elevação do gargalo. 
Tabela 6 - Adequação da utilização dos recursos de acordo com a demanda

\begin{tabular}{|c|c|c|c|c|c|c|}
\hline \multirow[b]{2}{*}{ Processo } & \multicolumn{2}{|c|}{ Tempo por processo } & \multirow{2}{*}{$\begin{array}{c}\begin{array}{c}\text { Tempo } \\
\text { disponível }\end{array} \\
\text { Dia* }^{*}\end{array}$} & \multicolumn{2}{|c|}{$\begin{array}{l}\text { Tempo necessário para atender } 1200 \text { unid. } \\
\text { de } C 1 \text { e } 1200 \text { unid. de } C 2\end{array}$} & \multirow{2}{*}{$\begin{array}{c}\text { Utilização } \\
\%\end{array}$} \\
\hline & $\mathrm{C} 1$ & $\mathrm{C} 2$ & & $\mathrm{C} 1=1200$ & $\mathrm{C} 2=1200$ & \\
\hline $\mathrm{P} 1$ & 6,11 & 6,11 & 30600 & 7332 & 7332 & $48 \%$ \\
\hline $\mathrm{P} 2$ & 9,78 & 9,78 & 30600 & 11730 & 11730 & $77 \%$ \\
\hline $\mathrm{P} 3$ & 9,67 & 9,67 & 30600 & 11604 & 11604 & $76 \%$ \\
\hline $\mathrm{P} 4$ & 12,13 & 12,13 & 30600 & 14556 & 14556 & $95 \%$ \\
\hline P5 & 9,92 & 9,92 & 30600 & 11904 & 11904 & $78 \%$ \\
\hline P6 & 6,91 & & 30600 & 8292 & & $27 \%$ \\
\hline P7 & & 6,06 & 30600 & & 7272 & $24 \%$ \\
\hline P8 & 9,38 & 9,38 & 30600 & 11256 & 11256 & $74 \%$ \\
\hline P9 & & 9,28 & 30600 & & 11136 & $36 \%$ \\
\hline P10 & 10,85 & 10,85 & 30600 & 13020 & 13020 & $85 \%$ \\
\hline P11 & 6,96 & 13,92 & 30600 & 8352 & 16704 & $82 \%$ \\
\hline $\mathrm{P} 12$ & & 9,62 & 30600 & & 11544 & $38 \%$ \\
\hline P13 & 5,8 & & 30600 & 6960 & & $23 \%$ \\
\hline
\end{tabular}

* Tempo expresso em segundos

Fonte: Autoria própria (2009)

A etapa de elevar a restrição do sistema para a empresa deve ser entendida por aumentar a capacidade de produção para os produtos $\mathrm{C} 1$ e C2. Essa decisão implica em fazer investimentos no setor de costura, contratando novos funcionários e/ou adquirindo novos equipamentos.

Uma vez identificado o gargalo (P2, M2) foi efetuada a elevação do mesmo. Esta elevação ocorreu através da contratação de um funcionário que ficou responsável pela operação P2 quando se produz $\mathrm{C} 2$ e pela operação $\mathrm{P} 11$ quando se produz $\mathrm{C} 1$, resultando no aumento da capacidade de $\mathrm{P} 2$ que passou a ter uma utilização de $77 \%$.

Com essa atitude se tornou possível atingir a demanda dada pelo mercado que é de 1200 peças de cada produto, ficando ainda tempo disponível no recurso P4 que é o com maior utilização entre os demais. Dessa forma a restrição deixou de ser interna e passou a ser uma restrição do mercado.

\subsection{Não deixar a inércia tomar conta do sistema}

Nessa etapa é importante estar consciente que após elevar a restrição do sistema, outra irá limitar a capacidade de gerar resultados para a empresa. Os cinco passos de focalização da TOC preconizam a necessidade dos gestores estarem atentos a essas novas restrições para que possam continuar o processo de aprimoramento contínuo. Voltar ao primeiro passo é rever todo o sistema em busca de novos pontos de alavancagem e romper novas restrições.

Para se romper as restrições, nem sempre é necessário que se façam grandes investimentos. A habilidade de reconhecer potenciais melhorias gera vantagem competitiva para as empresas que se utiliza de pequenos esforços para alavancarem seus negócios. 
A Tabela 7 e o Gráfico 2 apresentam uma simulação sobre o impacto da elevação de novas restrições e os investimentos necessários para alcançá-los.

Tabela 7 - Resultados obtidos com a simulação da elevação da restrição

\begin{tabular}{cccccc}
\hline $\begin{array}{c}\text { Elevação da } \\
\text { restrição }\end{array}$ & \multicolumn{2}{c}{ Demanda atendida* } & Ganho adicional & $\begin{array}{c}\text { Investimento } \\
\text { necessário }\end{array}$ & Resultado \\
\hline P2 & 1200 & $\mathrm{C} 2$ & - & - & - \\
De P2 para P4 & 1200 & 965 & $\mathrm{R} \$ 4.287,45$ & $\mathrm{R} \$ 973,20$ & $\mathrm{R} \$ 3.314,25$ \\
De P4 para P11 & 1600 & 1200 & $\mathrm{R} \$ 10.421,46$ & $\mathrm{R} \$ 2.533,20$ & $\mathrm{R} \$ 7.888,26$ \\
De P11 para P5 & 1484 & 1398 & $\mathrm{R} \$ 1.717,38$ & $\mathrm{R} \$ 2.688,20$ & $-\mathrm{R} \$ 970,82$ \\
De P5 para P2 & 1530 & 1600 & $\mathrm{R} \$ 782,46$ & $\mathrm{R} \$ 1.560,00$ & $-\mathrm{R} \$ 777,54$ \\
\hline
\end{tabular}

* valores em unidades

Fonte: Autoria própria (2009)

De acordo com a Tabela 7 podem-se observar as etapas de elevação das restrições a partir do estágio inicial em que o processo P2 era o gargalo. Para o cálculo do ganho adicional com a elevação do gargalo foi considerado um mês de 21 dias trabalhados. As elevações são descritas, a seguir:

De P2 para P4: Para se elevar a restrição de P2 para P4, ou seja, ao aumentar a capacidade produtiva de P2, o novo recurso a limitar a produção passa a ser P4. Foi preciso a contratação de mais um funcionário (O12) que representou um aumento na despesa operacional de $\mathrm{R} \$ 973,20$, valor que contempla as despesas com salário e encargos. É importante notar que embora P4 seja o novo gargalo, a simulação considerou a demanda de 1.200 peças por produto como a restrição do sistema. A Tabela 6 apresenta os cálculos dessa elevação. O resultado foi positivo em R\$ 3.314,25. Esta é a configuração em que se encontrava a empresa no momento desse estudo.

De P4 para P11: Antes de se elevar o gargalo de P4 para P11, foi preciso simular o aumento na demanda, que passou para 1600 peças por produto, fazendo com que a restrição deixasse de ser externa, do mercado, para novamente ser interna, da produção. Para atender a nova demanda P11, atingiu uma utilização de $109 \%$, sendo novamente preciso decidir entre produzir C1 ou C2, o maior ganho, $\mathrm{R} \$ 10.421,46$ foi obtido produzindo-se 1600 peças de $\mathrm{C} 1$ e 1398 peças de $\mathrm{C} 2$, que significou um resultado positivo de $\mathrm{R} \$ 7.888,26$. Nesse caso foi necessária a contratação de mais um operador (O13), no valor de R\$973,20 e a aquisição de uma máquina (M15), no valor de R\$1.560,00, perfazendo um total de $\mathrm{R} \$ 2.533,20$.

De P11 para P5: Foi preciso a contratação de mais um funcionário (O14) no valor de $\mathrm{R} \$$ 973,20 e a aquisição de uma máquina (M16) no valor de $\mathrm{R} \$ 1.715,00$, perfazendo um total de $\mathrm{R} \$ 2.688,20$. Porém a proximidade do percentual de utilização entre $\mathrm{P} 11$ e $\mathrm{P} 5$, não permitiu um aumento no ganho $(\mathrm{R} \$ 1.717,38)$ superior ao investimento, o que gerou um resultado negativo de $\mathrm{R} \$ 970,82$. 
De P5 para P2: Com a elevação anterior P2 passou a ser o novo gargalo, como operador O14 não pôde ser aproveitado na operação P2 por falta de equipamento, foi necessário comprar uma máquina (M17) no valor de R \$ 1.560,00, para esse propósito. Ainda assim o ganho adicional, no valor de $\mathrm{R} \$ 782,46$ foi menor que o investimento gerando um resultado negativo de $\mathrm{R} \$ 777,54$.

O Gráfico 2 ilustra os ganhos obtidos nas duas primeiras elevações e a inversão dos resultados da terceira e quarta tentativas.

Embora a TOC separe despesa operacional de investimento, a simulação chamou de investimento o esforço necessário para se elevar a restrição. Procurando tornar claro para os gestores o quanto será preciso gastar para se obter novos ganhos. No caso a contratação de um operador, significa um aumento na despesa operacional e um desembolso mensal, já a aquisição de uma máquina é um investimento que poderá ser depreciado. A simulação tem como objetivo prever cenários futuros e gerar informações para análises financeiras de investimento aprofundadas.

Gráfico 2- Ganho adicional x investimento necessário

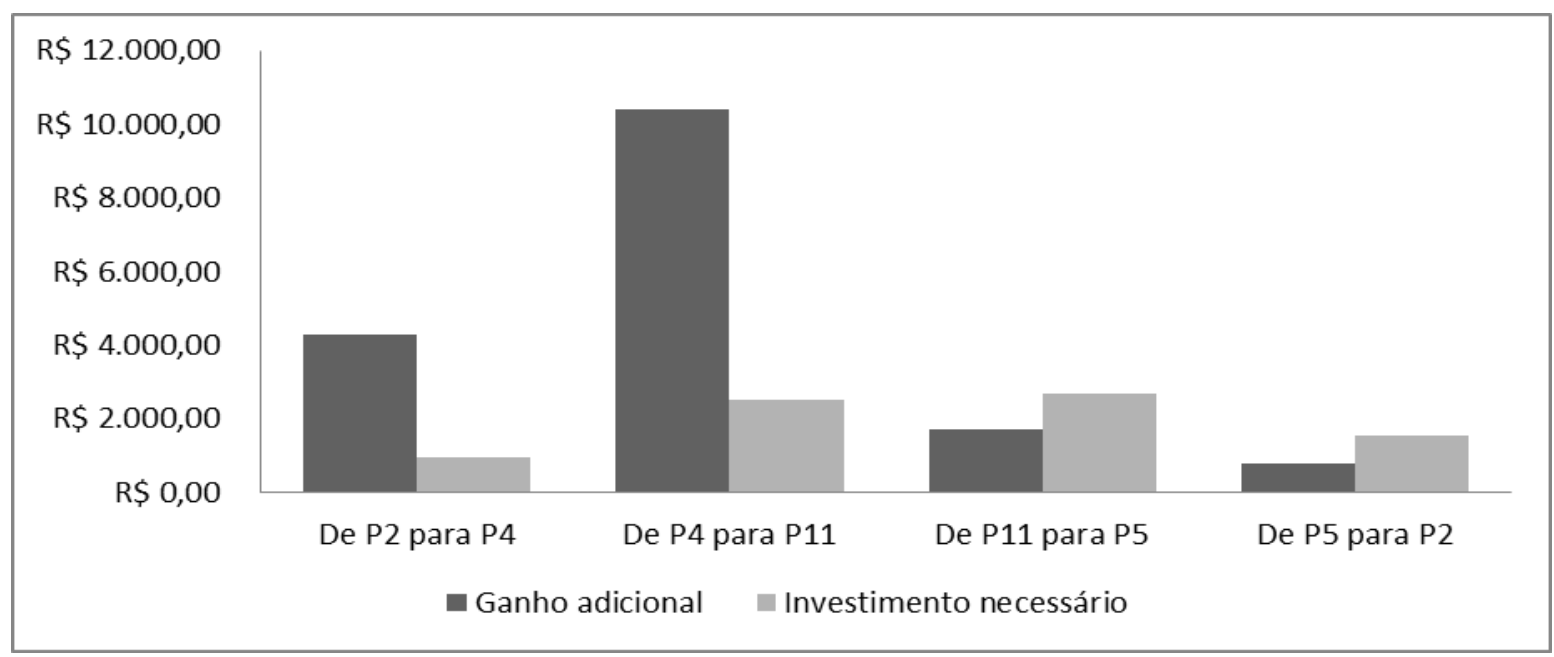

Fonte: Autoria própria

\section{Análise da aplicação}

Com base no que foi observado nos tópicos anteriores é possível verificar a contribuição que a abordagem da TOC dos cinco passos de focalização trouxe para a empresa de confecções, foco desse estudo.

Primeiro passo: Identificar a restrição do sistema. Foi possível através da análise dos tempos identificar o gargalo do sistema como sendo a operação P2 (onde são unidos os detalhes laterais dos produtos $\mathrm{C} 1$ e C2). A contribuição desse passo foi o de auxiliar os gestores de produção a priorizar seus esforços de melhoria contínua nessa operação. Em um primeiro momento buscando operadores mais qualificados e uma política de manutenção preventiva mais eficiente e em um segundo momento elevando a restrição. 
Segundo passo: Decidir como explorar a restrição do sistema. Nessa fase foi possível para a empresa planejar de forma simples o sistema de planejamento e controle da produção (PCP) com base na metodologia Tambor-Pulmão-Corda (TPC), que trouxe um sincronismo entre as etapas de produção. Também foi possível definir a prioridade na produção de C1 ou C2 quando não era possível atender a demanda total para os dois produtos.

Terceiro passo: Subordinar o sistema de produção às decisões acima. A fase de subordinação foi contemplada com a implantação do TPC que orienta todas as demais etapas a seguirem o planejamento do recurso gargalo, evitando desvios e garantindo um fluxo constante para o sistema.

Quarto passo: Elevar as restrições do sistema. Ao elevar a restrição do sistema de P2 para P4 foi possível à empresa não só aumentar o seu ganho como atender à sua demanda. Fortalecendo assim sua imagem frente aos clientes.

Quinto passo: Se a restrição tiver sido quebrada em um dos passos anteriores, retornar ao passo 1. Não deixar a inércia se transformar na restrição do sistema. Nesse ponto a simulação permitiu aos gestores enxergarem antes da execução o impacto que a elevação do gargalo terá no ganho da empresa e o investimento necessário para alcançá-lo. Embora a simulação tenha sido feita com base nos tempos médios dos operadores e máquinas disponíveis, ela retrata a tendência que será encontrada na realidade.

\subsection{Percepção do gestor da organização}

Esta parte do trabalho procurou relatar as percepções obtidas pelos gestores da empresa a partir da aplicação do estudo. Segundo a proprietária da empresa M. G. B. Sodré foram destacadas às seguintes melhorias:

Visão clara dos objetivos da produção: Antes da implantação da TOC não havia um ponto de controle da produção que permitisse um acompanhamento real do número de peças acabadas produzidas durante a jornada de trabalho. A eficiência das operações era controlada individualmente, uma vez que as operações possuíam tempos de processo diferentes eram geradas distorções no cálculo de peças produzidas durante o dia. Com a identificação do gargalo, foi possível controlar e acompanhar o fluxo de produção auxiliando na tomada de decisão gerencial.

Aumento de $40 \%$ nas vendas: Com a elevação dos gargalos foi possível à empresa atender um número maior de pedidos com prazos menores de entrega o que permitiu à equipe de vendas aumentarem os pedidos com clientes antigos e atender a novos.

Diminuição do inventário em 66\%: Com a implantação da metodologia TPC, os inventários ficaram atrelados às necessidades do gargalo o que gerou facilidade nos cálculos de compras de matéria-prima definindo valores de estoque mínimo e lotes de reposição, que até então não eram utilizados pela empresa. 
Diminuição do lead time de uma semana para dois dias: O sistema anterior de produção baseava-se na eficiência local das operações, procurando manter o pessoal o tempo todo ocupado, gerando altos níveis de estoque em processo e consequentemente maior tempo de atravessamento. Com a aplicação da metodologia TPC, o gargalo passou a regular o nível de estoque possibilitando entregar os pedidos com maior agilidade.

Melhora no desempenho das entregas: A melhoria no desempenho das entregas é função direta dos resultados obtidos no sistema de produção da empresa, que através da diminuição do lead time e melhor previsão e controle da produção pôde trabalhar com cronogramas de entrega realísticos, oferecendo aos seus clientes prazos factíveis de entrega e aumentando a credibilidade da empresa.

\section{Conclusão}

A modelagem desenvolvida no presente trabalho considerou a aplicação dos conceitos da Teoria das Restrições ao sistema de produção de uma empresa de confecções situada em Juiz de Fora, MG, Brasil.

Para o desenvolvimento da modelagem, os tempos de operação para a produção da linha de produtos foi cronometrado.

Como resultados principais, obteve-se:

A modelagem foi capaz de viabilizar a aplicação da TOC, com a identificação da estação de trabalho gargalo do sistema (estação P2).

Foi possível prever os impactos que mudanças no chão-de-fábrica causariam no fluxo de produção, antes que tais mudanças fossem efetuadas. Assim, com base na simulação da elevação dos gargalos, foi possível aos gestores visualizarem os impactos das mudanças sem ter que arcar com o ônus de implantá-las.

As informações levantadas foram utilizadas como dados de entrada para o suporte a análises financeiras, possibilitando ao gestor identificar até que ponto seria rentável para a empresa elevar o gargalo.

Recomenda-se que, devido ao recorte temporal da pesquisa, os parâmetros do modelo sejam atualizados e revisados com frequência.

Outra limitação da pesquisa é que não foram considerados fatores como o absenteísmo, quebra de máquinas, atrasos de fornecedores e outros que afetam o desempenho direto da empresa.

\section{Abstract}

This article analyzes the use of Theory of Constraints (TOC), in the production planning system of a clothing firm with 17 employees, situated in the city of Juiz de Fora, MG, Brazil. Data were collected between 01/02/2010 to 02/05/2010. At modeling process it was necessary to identify the 
flow and working time in each handmade work center. A sensitivity study about categories of cost and total production time were done. The results allowed identifying and raising bottlenecks and choosing the most appropriate option for the production system configuration.

Key-words: theory of constraints, process management, production management systems, apparel manufacturing.

\section{Referências}

BARCAUI, A. B.; QUELHAS, O. Corrente Crítica: uma alternativa à gerência de projetos tradicional. Revista Pesquisa e Desenvolvimento Engenharia de Produção. v. 2, p. 1-21. 2004.

CHAKRAVORTY, S. S. Improving a V-plant operation: a window manufacturing case study. Production and Inventory Management Journal. v. 41, n. 3, Third Quarter p. 37. 2000.

DA SILVA, M. C, BARRETO, M. L. G; DA SILVA, L. B. Construção de modelo matemático regressivo para racionalização dos tempos de processamento das atividades de pré-impressão de uma gráfica. Revista Gestão Industrial, v.5, n.4, p.168-182. 2009.

GOLDRATT, E. M.; COX J. A Meta: Um processo de aprimoramento contínuo. São Paulo: Educator, 1993.

GOLDRATT, E. M.; FOX, R. E. A corrida pela vantagem competitiva. São Paulo: IMAM, 1992.

GOLDRATT, E. M.; SCHRAGENHEIM, E.; PTAK, C. A. Necessary but not sufficient - a theory of constraints business novel. Great Barrington: North River Press, 2000.

GUIMARÃES, S. R., Cronoanálise para confecção. Curso de supervisor de confecção. SENAI, 2004. Apostila.

GUPTA, M. C. ; BOYD, L. H. Theory of constraints: a theory for operations management. International Journal of Operations \& Production Management. v. 28, n. 9-10, p. 991-1012. 2008.

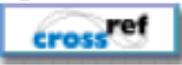

HO, T. F.; LI, R. K. Bottleneck-based heuristic dispatching rule for optimizing mixed tdd/idd performance in various factories. The International Journal of Advanced Manufacturing Technology. 2006.

KUO, T. C.; CHANG S. H.; HUANG, S. N. Due-date performance improvement using toc's aggregated time buffer method at a wafer fabrication factory. Expert Systems with Applications, v.36, n.2, p.1783-1792. 2009.

cross ref

LOCKAMY, A. I. Examining supply chain networks using v-a-t material flow analysis. Supply Chain Management: An International Journal, v.13, n.5, p.343-348. 2008.

cross ref

MABIN, V. J.; BALDERSTONE S. J.. The Performance of the Theory of Constraints Methodology: Analysis and Discussion of Successful Toc Applications. International Journal of Operations \& Production Management, v.23, n.5/6, p.28. 2003.

MOELlMANN, A. H.; ALBUQUERQUE A. S; CONTADOR, J. L.; MARINS, F. A. S. Aplicação da teoria das restrições e do indicador de eficiência global do equipamento para melhoria de produtividede em uma linha de fabricação. Revista Gestão Industrial. v.2, n.1, p. 89-105. 2006.

cross ref

NOGUEIRA, P.; COSTA, H. G. Estudo de percepções quanto às melhorias oriundas da implantação e prática do gerenciamento da rotina. Revista Gestão Industrial, v.5, n.4, p.1-23. 2009. 
NOGUEIRA, M. D. G. S.; GOMES K. G. B. Aplicação da teoria das restrições no laboratório de vestuário industrial da Ufpel.In: Encontro Nacional de Engenharia de Produção. Foz do Iguaçu, 2007. Anais... Foz do Iguaçu: ABEPRO,2007.

SCHRAGENHEIM, E.; RONEN, B. Buffer Management: a diagnostic tool for production control. Production and Inventory Management Journal, v.32, n. 2, Second Quarter p.74. 1991.

SEBRAE - Serviço Brasileiro de Apoio às Micro e Pequenas Empresas. Boletim estatístico de micro e pequenas empresas. Observatório Sebrae: $1^{\circ}$ Semestre, Brasília: 2005. Disponível em:

http://www.dce.sebrae.com.br/bte/bte.nsf/03DE0485DB219CDE0325701B004CBD01/\$File/NT000A8E66.pdf> . Acesso em: 14 de fev. de 2007.

SELLITTO, M. A. Processos de pensamento da toc como alternativa sistêmica de análise organizacional: uma aplicação em saúde pública. Gestão\&Produção, v.12, p.81-96. 2005.

cross ref

SINGH, R.; PRAKASH; KUMAR, S; TIWARI, M. Psycho-clonal based approach to solve a toc product mix decision problem. The International Journal of Advanced Manufacturing Technology, v.29, n.11, p.1194-1202. 2006.

cross ref

TORRES, F. G. Investigação sobre a aplicação da teoria das restrições (TOC) em uma empresa de confecções. 2009, 104f. Dissertação (Mestrado em Sistemas de Gestão) - Universidade Federal Fluminense, Niterói. 2009.

UMBLE, M. M. Analyzing Manufacturing Problems Using V-a-T Analysis. Production \& Inventory Management Journal, v.33, n.2, p.55-60. 1992.

\section{Dados dos autores:}

Nome completo: Helder Gomes Costa

Filiação institucional: Universidade Federal Fluminense - UFF

Departamento: Engenharia de Produção

Função ou cargo ocupado: Professor Associado

Endereço completo para correspondência (bairro, cidade, estado, país e CEP):

Rua Passo da Pátria, 156 - Sala 306 - Bloco E, São Domingos, Niterói, Brasil, CEP: 24210-240.

Telefones para contato: (21) 8892-2297

e-mail: hgc@pg.cnpq.br

Nome completo: Fábio Gonçalves Torres

Filiação institucional: Universidade Federal Fluminense - UFF

Departamento: Mestrado em Sistema de Gestão

Função ou cargo ocupado: Mestrando

Endereço completo para correspondência (bairro, cidade, estado, país e CEP):

Estrada União e Indústria, s/n, Km 182, Granjas Bethel, Juiz de Fora, MG, Brasil - 36033-120. 
Telefones para contato: (032) 8421-6566

e-mail: fabio@tred.com.br

Enviado em: 11/12/2011

Aprovado em: 17/06/2013 